\title{
Association of non-wheezing lower respiratory tract illnesses in early life with persistently diminished serum IgE levels
}

Fernando D Martinez, Debra A Stern, Anne L Wright, Lynn M Taussig, Marilyn Halonen and the Group Health Medical Associates

\begin{abstract}
Background - The role of lower respiratory tract illnesses (LRIs) in the development of allergies is not well understood. The relation of wheezing and non-wheezing LRIs to serum IgE levels and atopy was studied in 888 children.

Methods - Total serum IgE levels were measured at birth, nine months and six years of age; and interferon gamma production by blood mononuclear cells was measured at birth and nine months. Atopy was determined by skin prick tests at age six. Wheezing and non-wheezing LRIs up to age three were diagnosed by a physician. Results - Cord serum IgE levels were similar between all LRI groups and the no LRI group. Children who had wheezing LRIs until the age of three had IgE levels at nine months and at six years within normal ranges for age. In contrast, children who had a non-wheezing LRI before the nine month IgE sample had lower IgE levels at nine months and six years (geometric mean $1.8 \mathrm{IU} / \mathrm{ml}$ and $9.9 \mathrm{IU} / \mathrm{ml}$, respectively) compared with children who had no LRIs $(3.9 \mathrm{IU} / \mathrm{ml}$ and $38.3 \mathrm{IU} / \mathrm{ml}$, respectively). Children who had non-wheezing LRIs after the nine month IgE sample had normal nine month IgE levels (3.2 IUI ml) but decreased IgE levels at six years of age $(15 \cdot 7 \mathrm{IU} / \mathrm{ml})$. Children with more than one non-wheezing LRI before the age of three were less likely to be atopic than those with no LRI (odds radio $0 \cdot 2$ ). Interferon gamma production was higher in the non-wheezing LRI group at nine months than in the no LRI or wheezing LRI groups. Conclusions - Non-wheezing LRIs are associated with subsequent depression of IgE levels and reduced skin test reactivity.

(Thorax 1995;50:1067-1072)
\end{abstract}

Keywords: respiratory tract infections, IgE, interferon gamma.

of Pharmacology

M Halonen

University

of Arizona Health

Sciences Center,

Tucson, Arizona

85724, USA

Reprint requests to:

Dr F D Martinez.

Received 2 March 1995

Returned to authors

9 May 1995

Revised version received

7 July 1995

Accepted for publication

11 July 1995 development of allergies is not well understood. For many years the hypothesis that these infections could play a part in enhancing allergic sensitisation had many supporters. Frick and coworkers reported that allergic symptoms seemed to start immediately after viral infections in children of two allergic parents. ${ }^{1}$ More recent epidemiological studies have challenged this concept. In a large cohort study in the UK Strachan observed a striking inverse relationship between prevalence of allergic rhinitis and the number of older siblings in the household, but no association between allergic rhinitis and the number of younger siblings. ${ }^{2}$ The author suggested that the presence of older siblings could be associated with more viral infections in early life, and that these could somehow prevent allergic sensitisation. Von Mutius and coworkers reported an inverse relationship between the number of siblings in the household and the prevalence of at least one positive skin test to allergens in over 7000 children from East and West Germany. ${ }^{3}$

Viral infections accompanied by high levels of interferon gamma (IFN $\gamma$ ) and low levels of interleukin 4 (IL-4) may induce T helper (Th) cells to differentiate towards the Th 1 phenotype - that is, cells which produce IFN $\gamma$ but not IL4 or IL-5 and provide B cell help for the production of $\operatorname{IgM}, \operatorname{IgG}$, and IgA but not IgE antibodies. ${ }^{4}$ In contrast, Th cells encountering allergens in an environment of low or no IFN $\gamma$ and in the presence of IL-4 may differentiate towards the Th2 phenotype - that is, cells which produce IL- 4 and IL- 5 but not IFN $\gamma$ and provide $B$ cell help for the production of IgM, IgG, IgA, and IgE antibodies. ${ }^{4}$ IL-4 is thought to be the main cytokine inducing $B$ cells to commit to IgE synthesis. Based on these studies, Martinez proposed the hypothesis that frequent respiratory infections in early life could influence the process of clonal selection of $T$ helper cells. ${ }^{5}$ According to this hypothesis, both genetic and environmental influences determine which $\mathrm{T}$ helper cell phenotype becomes more prevalent after the first months of life. Preferential encounter with infectious antigens might assist in the selection of Th1 cells.

The purpose of this study was to determine if IgE levels, skin test reactivity, and ex vivo evidence of lymphocyte function would provide support for the hypothesis that lower respiratory tract infections in early life may enhance the selection of Th1-like $T$ cells and decrease or prevent the development of allergy later in life. For this purpose we used data from a large longitudinal study of acute and chronic respiratory illnesses in children who have been followed since birth in Tucson, Arizona, USA.
Methods

The subjects were enrolled at birth. ${ }^{6}$ Mothers who used the services of a Health Maintenance Organisation (HMO) in Tucson and gave birth to healthy babies during the enrollment period 
(May 1980-October 1984) were contacted by a study nurse. A total of 1246 infants ( $78 \%$ of those contacted) were enrolled. Informed consent was obtained from parents of participating subjects and the study was approved by the Human Subjects Committee of the University of Arizona.

Ethnicity, maternal education, and the parental history of asthma and allergies were determined by a questionnaire completed by the parents at enrollment. A diagnosis of asthma in either or both parents was considered a positive parental history of asthma for the child.

\section{LOWER RESPIRATORY TRACT ILLNESSES}

Parents were instructed to take their child to their paediatrician if he/she developed symptoms of a lower respiratory tract illness (LRI) (deep or "wet" chest cough, wheezing, hoarseness, stridor, or shortness of breath). For each LRI the physicians completed a standardised form on signs and symptoms present at the time of examination and recorded a diagnosis of laryngotracheobronchitis (croup), pneumonia, bronchitis, bronchiolitis, or other. The study nurses, who were located in the paediatricians' offices, obtained additional historical information and pharyngeal swabs for culturing for respiratory viruses (respiratory syncytial virus, parainfluenza, adenovirus, influenza, and others) plus mycoplasma and chlamydia. Culture techniques have been described in detail. ${ }^{7}$ Follow up for LRIs continued for the first three years of life and included 888 infants $(71.3 \%)$ who remained under the care of the paediatricians. Of these children, $51 \%$ were girls, and $75 \%$ were non-Hispanic white subjects, $14 \%$ were Hispanic, and $11 \%$ had a multiethnic background.

A comparison of the children who were eligible for this study (that is, who had completed three year follow up data for lower respiratory illness, $\mathrm{n}=888$ ) with those who were not $(\mathrm{n}=$ 358) showed that family history of asthma and allergies and ethnic distribution were similar in the two groups. The only significant difference noted was that children with complete data were more likely to belong to families with higher levels of maternal education.

Reports by the paediatricians at the time of the acute illnesses were used to classify LRIs as wheezing or non-wheezing; wheezing information was missing for 13 children and they were subsequently excluded from the analyses. For clinical characterisation of the LRIs with reference to fever, duration, agent and diagnosis, the first LRI for each child in each year was independently categorised as wheezing or non-wheezing. For other analyses the children were categorised into wheezing or non-wheezing LRI groups based on the LRI history before the age of three years. In addition, to examine the effect of wheezing LRI and non-wheezing LRI on nine month IgE levels, the occurrence of the first LRI before or after the sampling date of the nine month IgE sample was determined. For both categories, those children who had both wheezing LRI and non-wheezing LRIs were included in the wheezing LRI group.
TOTAL SERUM IGE LEVELS

Total serum IgE levels were measured in 792 umbilical cord blood samples. A second sample was obtained from 704 subjects at a well baby check-up at a median age of 9.3 months, range 6.8-28.8 months ("nine month" sample). Since IgE levels increase rapidly during this time period, $\mathrm{IgE}$ values were adjusted for age using standard regression techniques. ${ }^{8} \mathrm{~A}$ third blood sample was obtained at a median age of 6.3 years, range $4 \cdot 4-9.8$ years, ("six year" survey). Some children refused phlebotomy at this age and 456 children were tested.

Total serum IgE levels were assayed in the cord, nine month and six year blood samples by the same Phaedebas radioimmunosorbent test (PRIST) using commercially available kits (Pharmacia Diagnostics, Piscataway, NJ, USA) as previously reported. ${ }^{8}$ All samples were assayed in duplicate and results expressed in $\mathrm{IU} / \mathrm{ml}$.

\section{ALLERGY SKIN PRICK TEST}

Allergy skin tests were performed at the six year survey in 642 children. Extracts of seven common Tucson aeroallergens were obtained from Hollister-Stier Laboratories (Everett, Washington) including house dust mix (1:10 $\mathrm{w} / \mathrm{v})$, Alternaria alternata $(1: 100 \mathrm{w} / \mathrm{v})$, bermuda grass $(1: 20 \mathrm{w} / \mathrm{v})$, careless weed $(1: 20 \mathrm{w} / \mathrm{v})$, and olive, mesquite, and mulberry trees $(1: 20 \mathrm{w} /$ v). After 20 minutes the size of the weal elicited by each allergen was recorded as the sum of the two diameters at right angles to each other (in $\mathrm{mm}$ ). Weal sizes of $3 \mathrm{~mm}$ or more were considered positive. A subject was considered atopic if she/he had at least one positive skin test to any of the aeroallergens.

\section{INTERFERON GAMMA PRODUCTION BY BLOOD} MONONUCLEAR CELLS

After February 1983 studies of mononuclear cell function were added to the protocols and all 296 infants subsequently enrolled were eligible. Blood mononuclear cell samples were collected at birth and at the nine month check-up (data used herein were limited to those from samples collected in the first year). Of the infants with complete three year LRI follow up information and complete wheezing information $(n=875)$, 43 had cord blood and 92 had nine month IFN $\gamma$ studies.

The main factors determining exclusion from the studies of IFN production were parental refusal to give consent for phlebotomy; the feasibility of transporting the samples from the outpatient offices to the laboratory; and the timely availability of trained personnel to perform the analyses. In addition, technical factors such as the amount of blood available prevented the assessment of IFN $\gamma$ production in a small number of subjects.

IFN $\gamma$ production by blood mononuclear cells Blood was collected in heparin $(5 \mu \mathrm{l} / \mathrm{ml})$ and processed within 12 hours of collection. Blood was layered on Lymphocyte Separation 
Medium (Litton Bionetics, Kensington, MD, USA) after diluting 1:2 with RPMI-1640 medium. ${ }^{9}$ The cells at the blood/medium interface were collected, washed twice with $\mathrm{Ca}^{2+}$ free and $\mathrm{Mg}^{2+}$-free phosphate buffered saline, and resuspended in RPMI-1640 medium. A haemocytometer total cell count and chamber differential were performed to estimate the percentage of mononuclear cells.

Immediately after cell separation, $10^{6}$ blood mononuclear cells were incubated in $1 \mathrm{ml}$ aliquots of RPMI-1640 medium supplemented with $5 \%$ heat inactivated fetal calf serum, $300 \mu \mathrm{g} / \mathrm{ml}$ glutamine, $220 \mu \mathrm{g} / \mathrm{ml}$ pyruvic acid, and $50 \mu \mathrm{g} / \mathrm{ml}$ gentamicin at $37^{\circ} \mathrm{C}$ in a $5 \%$ $\mathrm{CO}_{2}$ air atmosphere. Cells were stimulated with $10 \mu \mathrm{g} / \mathrm{ml}$ concanavalin A (ConA; Pharmacia, Piscataway, NJ, USA) and $10 \mathrm{ng} / \mathrm{ml}$ phorbal myristate acetate (PMA; Sigma Chemical Co., St Louis, MO, USA). Supernatant fluids from these cells and from unstimulated cells were harvested after 20 hours and stored at $-70^{\circ} \mathrm{C}$ for IFN testing.

IFN $\gamma$ bioassay

IFN $\gamma$ titre determinations were carried out on the supernatant fluids using a Sindbis virusWISH cell system. ${ }^{9}$ Triplicate $\log _{3}$ serial dilutions of the fluids were incubated with the WISH-cell monolayers in flat bottom microtainer wells for eight hours before the addition of a previously titrated amount of Sindbis virus. ${ }^{9}$ The mean highest $\log _{3}$ dilution of supernatant fluid causing a $50 \%$ reduction in cytopathic effect was determined as the end point, and the reciprocal of this dilution was recorded as the IFN $\gamma$ titre. Each assay included a leucocyte IFN standard (National Institutes of Allergy and Infectious Diseases, Bethesda, MD, USA) to control for reproducibility of the test system. Virus titrations in supernatant fluids from unstimulated cells, medium containing ConA and PMA, and medium only were used as negative controls.

In a subset of 16 blood samples (randomly selected) the type of IFN produced under the test conditions was determined. Each sample was aliquoted and incubated for 30 minutes at room temperature with pretitred antibody to IFN $\alpha, \beta$ or $\gamma .{ }^{9}$ After incubation, the samples were added to the WISH-cell monolayers and titrated as above for quantitating IFN. A fourfold or greater decrease in IFN $\gamma$ titre, but not in IFN $\alpha$ or IFN $\beta$, was obtained in all cases.

\section{STATISTICAL ANALYSES}

Statistical analyses were performed using the Statistical Package for the Social Sciences (SPSS) for UNIX, version $4 \cdot 0$. Total serum IgE values were $\log$ normally distributed and results expressed as geometric mean in $\mathrm{IU} / \mathrm{ml}$. IFN $\gamma$ titres were $\log _{3}$ normally distributed and results expressed as the $\log _{3}$ titre. Statistical analyses involving these variables were performed using standard parametric techniques, including analysis of variance with Duncan multiple range test used to assess differences between group means. $\chi^{2}$ tests were used to assess differences in proportions. A $p$ value of $<0.05$ (two tailed) was considered statistically significant for all tests.

\section{Results}

Most of the children $(51 \%, 442 / 875)$ had at least one LRI during the first three years of life. When grouped for number and association with wheezing, $11 \%$ had one non-wheezing LRI, $2 \%$ had more than one non-wheezing LRI, $23 \%$ had one wheezing LRI, and $14 \%$ had more than one wheezing LRI. Non-wheezing LRIs were most often diagnosed as laryngotracheobronchitis by the paediatricians through all three years, whereas wheezing LRIs were most often diagnosed as bronchiolitis (table 1). Results of viral studies showed that wheezing LRIs were frequently associated with RSV isolates whereas either parainfluenza or no agent was more often identified in non-wheezing LRIs. Prevalence of fever was similar in both wheezing LRI and non-wheezing LRI groups. Parents whose children were diagnosed with non-wheezing LRIs brought them to the physician for examination significantly earlier during the illness than those with wheezing LRIs in years 1 and 2 (table 1 ). No relation was found between serum IgE levels at any age and viral aetiology of the LRIs.

Incidence of wheezing LRI or non-wheezing LRI in the first three years of life did not relate significantly to cord serum IgE levels (data not shown). Serum IgE levels at nine months were

Table 1 Characteristics of the first wheezing and non-wheezing LRIs occurring in years 1, 2 and 3

\begin{tabular}{|c|c|c|c|c|c|c|}
\hline & \multicolumn{2}{|l|}{ Year 1 LRI } & \multicolumn{2}{|c|}{ Year $2 L R I$} & \multicolumn{2}{|c|}{ Year $3 L R I$} \\
\hline & $\begin{array}{l}\text { Wheeze } \\
(n=191)^{*}\end{array}$ & $\begin{array}{l}\text { Non-wheeze } \\
(n=52)\end{array}$ & $\begin{array}{l}\text { Wheeze } \\
(n=129)\end{array}$ & $\begin{array}{l}\text { Non-wheeze } \\
(n=75)\end{array}$ & $\begin{array}{l}\text { Wheeze } \\
(n=79)\end{array}$ & $\begin{array}{l}\text { Non-wheeze } \\
(n=73)\end{array}$ \\
\hline Fever $>37 \cdot 0^{\circ} \mathrm{C}$ & $68 \cdot 1 \dagger$ & $72 \cdot 7$ & $75 \cdot 3$ & $84 \cdot 7$ & $82 \cdot 5$ & $79 \cdot 0$ \\
\hline Illness duration $\leqslant 1$ day & $5 \cdot 4 \ddagger$ & $34 \cdot 0$ & $11 \cdot 8 \ddagger$ & $26 \cdot 2$ & $13 \cdot 7$ & $13 \cdot 2$ \\
\hline \multicolumn{7}{|l|}{ Agent } \\
\hline RSV & $49 \cdot 5 \ddagger$ & $14 \cdot 3$ & $32 \cdot 2$ & $22 \cdot 7$ & $38 \cdot 3$ & $20 \cdot 8$ \\
\hline Parainfluenza & $10 \cdot 2$ & $18 \cdot 4$ & $10 \cdot 7 \ddagger$ & $27 \cdot 3$ & $11 \cdot 7$ & $20 \cdot 8$ \\
\hline Other & $13 \cdot 4$ & $18 \cdot 4$ & $20 \cdot 7$ & $22 \cdot 7$ & $8 \cdot 3$ & $20 \cdot 8$ \\
\hline None identified & $26 \cdot 9 \ddagger$ & $49 \cdot 0$ & $36 \cdot 4$ & $27 \cdot 3$ & $41 \cdot 7$ & $37 \cdot 7$ \\
\hline \multicolumn{7}{|l|}{ Diagnosis } \\
\hline Croup & $7 \cdot 3 \ddagger$ & $75 \cdot 0$ & $15 \cdot 5 \ddagger$ & $60 \cdot 0$ & $10 \cdot 1 \ddagger$ & $46 \cdot 6$ \\
\hline Bronchiolitis & $81 \cdot 2 \ddagger$ & $7 \cdot 7$ & $58 \cdot 1 \neq$ & $1 \cdot 3$ & $40 \cdot 5 \ddagger$ & $2 \cdot 7$ \\
\hline Pneumonia & $4 \cdot 2$ & 11.5 & $8 \cdot 5^{\circ}$ & $9 \cdot 3$ & $11 \cdot 4^{\circ}$ & $13 \cdot 7$ \\
\hline Bronchitis & $2 \cdot 6$ & $3 \cdot 8$ & $10 \cdot 1 \ddagger$ & $25 \cdot 3$ & $27 \cdot 8$ & $34 \cdot 2$ \\
\hline Other & $4 \cdot 7$ & 1.9 & $7 \cdot 8$ & $4 \cdot 0$ & $10 \cdot 1$ & $2 \cdot 7$ \\
\hline
\end{tabular}

* Some percentages based on slightly different sample sizes due to missing information.

$\dagger$ Results are expressed as \% of total subjects in each column.

$\ddagger \mathrm{p}<0 \cdot 05$ compared with non-wheezing LRI group. 


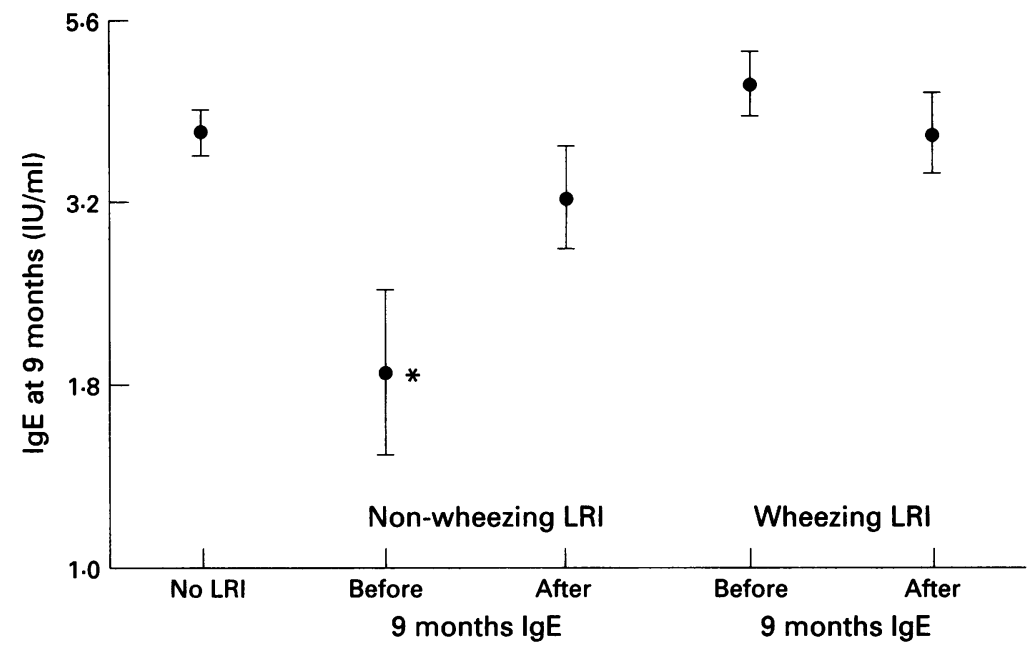

Figure 1 Total serum IgE levels at nine months of age in relation to wheezing LRIs and non-wheezing LRIs before or after the nine month IgE sample. Children who had a nonwheezing LRI before the nine month IgE sample $(n=20)$ had significantly lower nine month IgE levels $(* p<0 \cdot 05)$ than children who had wheezing LRIs before $(n=170)$ or after $(n=105)$ the nine month sample or who had no LRIs $(n=339)$. The IgE level of children who had a non-wheezing LRI after the nine month sample $(n=70)$ was not significantly different from the IgE levels of other LRI groups.

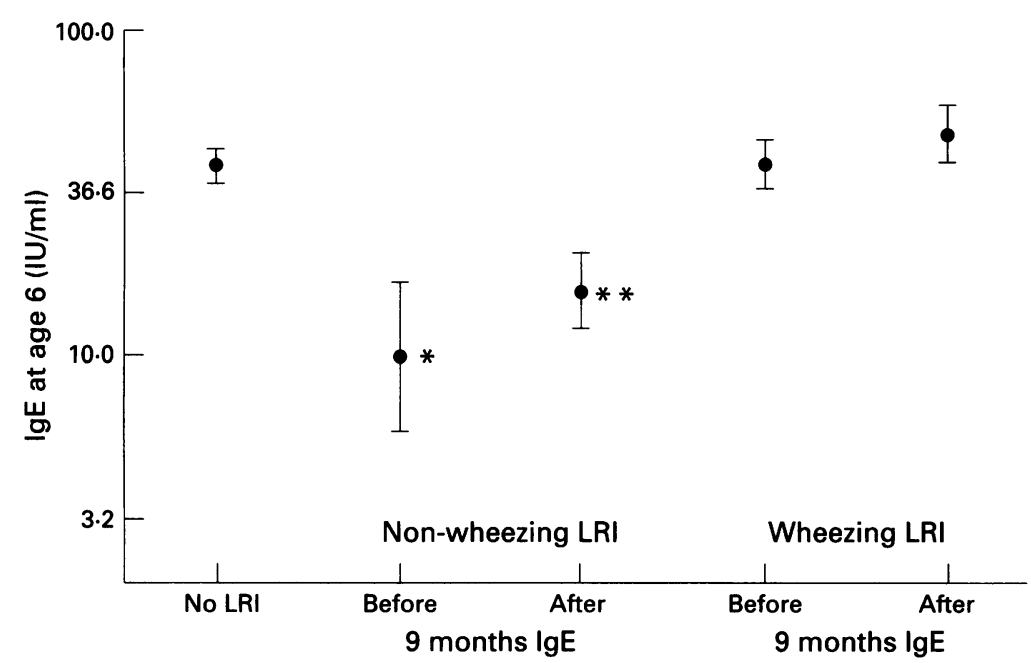

Figure 2 Total serum IgE levels at six years of age in relation to the occurrence of wheezing LRIs and non-wheezing LRIs before or after the nine month IgE sample. Children who had a non-wheezing LRI before the nine month IgE sample $(n=11)$ had significantly lower IgE levels $(* p<0.05)$ than children who had a wheezing LRI before $(n=91)$ or after $(n=69)$ the nine month sample or who had no LRIs $(n=210)$. The IgE level at six years of children who had a non-wheezing LRI after the nine month sample $(n=37)$ was also significantly lower than those with no LRI and wheezing $L R I$ $(* * p<0 \cdot 01)$. who had their first non-wheezing LRI after the nine month IgE sample had nine month IgE levels that were not significantly different from those of children with no LRIs or with wheezing LRIs (fig 1).

Figure 2 shows serum IgE levels at the age of six for the same five groups shown in fig 1 . At this age, children who had non-wheezing LRIs before and after the nine month IgE sample had significantly decreased IgE levels compared with children who had wheezing LRIs or no LRIs (fig $2 ; \mathrm{p}<0 \cdot 05$ ).

In table 2 children were divided according to the number of wheezing or non-wheezing LRIs up to the age of three and serum IgE levels and skin test reactivity at the age of six were compared between groups. IgE levels at six years were significantly lower in children who had one or more than one non-wheezing LRI than in children who had wheezing LRIs or no LRIs (table $2 ; \mathrm{p}<0.05$ and $\mathrm{p}<0.01$, respectively). Moreover, the 13 children who had more than one non-wheezing LRI had a geometric mean IgE level at age six that was more than three times lower than those who had no LRIs or who had wheezing LRIs (table 2). IgE levels of children who had both wheezing LRIs and non-wheezing LRIs were not significantly different from those who had only wheezing LRIs. As indicated earlier, children who had both wheezing LRIs and non-wheezing LRIs were placed in the wheezing LRI group for these analyses.

Children with more than one non-wheezing LRI were significantly less likely to be skin test positive for local aeroallergens than those with no LRI history (odds ratio $0 \cdot 2,95 \%$ confidence interval $0 \cdot 1$ to $1 \cdot 0, \mathrm{p}<0.05$; table 2 ).

There was no significant difference in parental history of asthma between children who had non-wheezing LRIs or wheezing LRIs ( $24 \%$ and $29 \%$, respectively), although both LRI groups had a significantly greater frequency of parental asthma history than the children who had no LRIs (18\%). Furthermore, the pattern of decreased IgE levels associated with non-wheezing LRIs was similar for children with or without a parental history of asthma.

Production of IFN $\gamma$ by peripheral blood mononuclear cells collected at the age of nine months was significantly higher among children who had non-wheezing LRIs than among either children who had no LRIs or those who had wheezing LRIs ( $<<0.05$; table 3$)$. IFN $\gamma$ production by blood mononuclear cells obtained at birth tended to show a similar relation to

Table 2 Relation of IgE levels and atopy at the age of six to wheezing or non-wheezing LRI history up to three years of age

\begin{tabular}{|c|c|c|c|c|c|c|c|}
\hline \multirow[t]{2}{*}{ LRI history to age 3} & \multicolumn{3}{|c|}{ Total serum IgE (IU/ml) } & \multicolumn{4}{|c|}{ Skin test reactivity } \\
\hline & $n$ & Geometric mean & $(95 \% C I)$ & $n$ & $\%$ Positive & $O R^{*}$ & $(95 \% C I)$ \\
\hline $\begin{array}{l}\text { No LRI } \\
1 \text { Non-wheezing LRI } \\
>1 \text { Non-wheezing LRI } \\
1 \text { Wheezing LRI } \\
>1 \text { Wheezing LRI }\end{array}$ & $\begin{array}{r}210 \\
45 \\
13 \\
115 \\
73\end{array}$ & $\begin{array}{l}38 \cdot 3 \\
16 \cdot 2 \dagger \\
12 \cdot 0 \ddagger \\
40 \cdot 5 \\
43 \cdot 3\end{array}$ & $\begin{array}{r}(30.2 \text { to } 48 \cdot 6) \\
(9.8 \text { to } 26.6) \\
(4.2 \text { to } 34 \cdot 1) \\
(29.5 \text { to } 55 \cdot 6) \\
(29.9 \text { to } 62.9)\end{array}$ & $\begin{array}{r}314 \\
62 \\
15 \\
152 \\
99\end{array}$ & $\begin{array}{l}40 \cdot 4 \\
35 \cdot 5 \\
13 \cdot 3 \\
41 \cdot 4 \\
39 \cdot 4\end{array}$ & $\begin{array}{l}-\overline{0 \cdot 8} \\
0 \cdot 25 \\
1 \cdot 0 \\
1 \cdot 0\end{array}$ & $\begin{array}{l}(0.5 \text { to } 1.4) \\
(0.1 \text { to } 1.0) \\
(0.7 \text { to } 1.6) \\
(0.6 \text { to } 1.5)\end{array}$ \\
\hline
\end{tabular}

* Odds ratio computed in reference to no LRI group.

$\dagger p<0.01, \ddagger p<0.05$ versus no LRI and wheezing LRI groups; overall analysis of variance $F=4 \cdot 2, p=0.002$. $\oint \mathrm{p}<0.05$ versus no LRI group. 
Table 3 Relation of blood mononuclear cell IFN production at birth and nine months to wheezing or non-wheezing LRI history up to three years of age

\begin{tabular}{|c|c|c|c|c|c|c|}
\hline \multirow[t]{2}{*}{ LRI history to age 3} & \multicolumn{3}{|c|}{$\log _{3} I F N \gamma$ titre } & \multicolumn{3}{|c|}{$\log _{3} I F N \gamma$ titre } \\
\hline & $n$ & Cord mean & $(95 \% C I)$ & $n$ & 9 month mean & $(95 \% C I)$ \\
\hline $\begin{array}{l}\text { No LRI } \\
\geqslant 1 \text { Non-wheezing LRI } \\
\geqslant 1 \text { Wheezing LRI }\end{array}$ & $\begin{array}{r}22 \\
6 \\
15\end{array}$ & $\begin{array}{l}2 \cdot 5 \\
3 \cdot 3 \\
2 \cdot 9\end{array}$ & $\begin{array}{l}(1.7 \text { to } 3 \cdot 2) \\
(1.6 \text { to } 4.9) \\
(2 \cdot 2 \text { to } 3 \cdot 7)\end{array}$ & $\begin{array}{l}41 \\
10 \\
41\end{array}$ & $\begin{array}{l}3 \cdot 0 \\
4 \cdot 2 \\
3 \cdot 4\end{array}$ & $\begin{array}{l}(2.5 \text { to } 3.4) \\
(3.0 \text { to } 5.4)^{*} \\
(3.0 \text { to } 3.8)\end{array}$ \\
\hline
\end{tabular}

${ }^{*} \mathrm{p}<0.05$ versus no LRI group; overall analysis of variance $\mathrm{F}=3 \cdot 8, \mathrm{p}<0.05$.

LRIs, but because the differences did not reach statistical significance no definite conclusion could be reached concerning cord blood cell IFN $\gamma$ values (table 3).

\section{Discussion}

In this study we assessed the number and characteristics of the lower respiratory illnesses occurring during the first three years of life. In this regard, it should be noted that our objective was not to study the incidence of all respiratory infections during early life. Indeed, most respiratory infections that occur in infants are asymptomatic or are associated with very mild symptoms. Therefore, this is a study of the more severe respiratory illnesses since, for a child to be diagnosed as having a LRI, he or she must have had an infection severe enough to motivate parents to seek medical attention. We distinguished between wheezing LRIs and non-wheezing LRIs because we have previously shown that these two forms of LRI are associated with very different risk factors during the first three years of life. ${ }^{10-13}$

Children who had non-wheezing LRIs early in life had significantly lower IgE levels at nine months and at six years than children who had wheezing LRIs or children who had no LRIs. Our data suggest the possibility that the lower nine month IgE levels observed in subjects who had non-wheezing LRIs may have been triggered by the non-wheezing LRI itself. This is supported by the fact that serum IgE levels were not decreased in those children sampled before any non-wheezing LRI developed; only in children whose LRIs occurred before sampling were serum IgE levels significantly lower than those of children with no LRIs. We hypothesise that, in children with non-wheezing LRIs, the immune response to the virus produces specific, persistent selection of Th1-like $\mathrm{T}$ helper clones. Development of such Th1 subsets is probably important because many viruses are more effectively controlled by a predominant Th1-type immune response. ${ }^{14}$ The Th1-type cell is also a potent inhibitor of the proliferation of Th2 clones. ${ }^{15}$ It is conceivable that the cytokines produced during the immune response to viruses might influence responses to other antigens being simultaneously encountered. The increased capacity of mitogen stimulated blood mononuclear cells to produce IFN $\gamma$ among children with non-wheezing LRIs supports the possibility that non-wheezing LRIs provide a non-antigenspecific influence in the Th1 direction.

Our data do not offer a direct explanation for the observed differences in subsequent IgE levels between children who had wheezing LRIs or non-wheezing LRIs. Infectious agents were associated with the majority of LRIs in both groups. It is unlikely, however, that the incidence of infection per se was different - that is, that the non-wheezing LRI illnesses were largely of a non-viral aetiology - since fever was equally prevalent in both groups. Moreover, the effects observed among children with nonwheezing LRIs were not dependent upon whether a virus was detected or upon the type of virus isolated. Most of the children with non-wheezing LRIs had diagnoses of laryngotracheobronchitis (or croup), and in most cases parents consulted physicians within 24 hours after the beginning of the condition. This urgency suggests that these children may have been more acutely ill than most of those who consulted for wheezing LRIs.

In a previous study using this same cohort we showed that most young children who wheeze during LRIs early in life have a benign prognosis and have lung function decrements consistent with a smaller size of the intrapulmonary airways measured shortly after birth. ${ }^{16}$ In contrast, non-wheezing LRIs are unrelated to airway size. ${ }^{11}$ These findings raise the possibility that, whereas clinical expression of disease in nonwheezing LRIs may be a function of the intensity of the immune response to infection (with consequent abundant mucus accumulation, airway oedema and "croupy cough"), clinical expression of disease in wheezy infants may be mainly a function of airway size before the LRI developed. A more intense immune response to viruses may thus imply stronger activation of antigen-presenting cells and possibly increased production of cytokines that enhance IFN $\gamma$ production by Th1type cells (for example, interleukin-12). ${ }^{17}$

The possibility that a viral insult may affect the subsequent immune response to aeroallergens is compatible with the results of several recent epidemiological studies. These include the reports of an inverse relation between the number of siblings and prevalence of atopy and allergic rhinitis in addition to other lines of evidence strongly suggesting an inverse relation between frequency of infections in childhood and allergic symptoms. ${ }^{2318-20}$ Von Mutius and coworkers, for example, compared prevalence of atopy (as assessed by allergy skin prick tests), bronchial hyperresponsiveness to cold air, and respiratory symptoms in children living in East and West Germany at the time of the reunification of that country. ${ }^{3}$ They found that symptoms usually related to respiratory infection were much more prevalent in East Germany, while atopy, asthma, and bronchial hyperresponsiveness were significantly more prevalent in West Germany. Because these 
populations are genetically similar, the authors concluded that environmental factors such as air pollution or early frequent contact with other children in day care settings increased respiratory infections in early life in East Germany, and these environmental factors may thus have reduced allergic sensitisation in that part of the country when compared with West Germany.

We cannot exclude the possibility that both the tendency to develop non-wheezing LRIs and to have lower levels of IgE may be due to a common, unknown genetic or environmental factor. Subjects congenitally predisposed to have a preponderance of IFN $\gamma$ producing blood mononuclear cells may have more brisk reactions to viral infections and, thus, may be prone to have more severe symptoms during these infections. We could not demonstrate a significant increase in IFN $\gamma$ at birth in subjects who subsequently developed non-wheezing LRIs, but our group size is small and it is also possible that $T$ cells may be too immature at birth to allow for meaningful responses to mitogen stimulation. ${ }^{21}$ Further studies are thus needed to assess whether viral infections themselves are responsible for the changes in IgE production observed in children with nonwheezing LRIs. We suggest, however, that our findings give further credence to the hypothesis that genetic and environmental factors regulating the preferential expansion of different clones of $T$ helper cells in early life may play decisive roles in establishing the atopic phenotype. ${ }^{15}$

The Group Health Medical Associates are Drs John Bean, Henry Bianchi, John Curtiss, John Ey, Alejandro Sanguineti, Barbara Smith, Terry Vondrak and Neil West, and Ms Maureen McLellan, RN, PNP

Studies sponsored by NIH SCOR Grant HL14136.

1 Frick OL, German DF, Mills J. Development of allergy in children I: Association with virus infections. $\mathcal{F}$ Allergy Clin Immunol 1979;63:228-41.

2 Strachan DP. Hay fever, hygiene, and household size. $B M \mathcal{F}$ 1989;299:1259-60.

3 von Mutius E, Martinez FD, Fritzsch C, Nicolai T, Reitmeir $\mathrm{P}$, Thiemann $\mathrm{HH}$. Skin test reactivity and number of siblings. $B M \mathcal{F}$ 1994;308:692-5.
4 Romagnani S. Induction of TH1 and TH2 responses: a key role for the 'natural' immune response? Immunol Today 1992;13:379-81

5 Martinez FD. Role of viral infections in the inception of asthma and allergies during childhood: could they be protective? Thorax 1994;49:1189-91.

6 Taussig LM, Wright AL, Morgan WJ, Harrison HR, Ray CG, The Group Health Medical Associates. The Tucson CG, The Group Health Medical Associates. The Tucson
Children's Respiratory Study: I. Design and imChildren's Respiratory Study: I. Design and im-
plementation of a prospective study of acute and chronic plementation of a prospective study of acute and chronic
respiratory illness in children. Am $\mathcal{F}$ Epidemiol 1989;129: 1219-31.

7 Wright AL, Taussig LM, Ray CG, Harrison HR, Holberg CJ, the Group Health Medical Associates. The Tucson Children's Respiratory Study. II. Lower respiratory tract illness in the first year of life. Am $\mathcal{F}$ Epidemiol 1989;129: $1232-46$.

8 Halonen M, Stern D, Lyle S, Wright A, Taussig L, Martinez FD. Relationship of total serum IgE levels in cord and 9month sera of infants. Clin Exp Allergy 1991;21:235-41.

9 Kibler R, Hicks MJ, Wright AL, Taussig LM. A comparative analysis of cord blood and adult lymphocytes: interleukin2 and interferon production, natural killer cell activity, and lymphocyte populations. Diagn Immunol 1986;4:201-8.

10 Martinez FD, Morgan WJ, Wright AL, Holberg CJ, Taussig LM, Group Health Medical Associates. Diminished lung function as a predisposing factor for wheezing respiratory illness in infants. $N$ Engl $\mathcal{F}$ Med 1988;319:1112-7.

11 Martinez FD, Morgan WJ, Wright AL, Holberg C. Taussig LM, GHMA Personnel Associates. Initial airway function is a risk factor for recurrent wheezing respiratory illnesses during the first three years of life. Am Rev Respir Dis 1991; during the first 2 .6.

12 Wright AL, Holberg CJ, Martinez FD, Taussig LM, and the Group Health Medical Associates. Relationship of parental smoking to wheezing and nonwheezing lower respiratory tract illnesses in infancy. F Pediatr 1991;118: 207-14.

13 Wright AL, Holberg CJ, Martinez FD, Morgan WJ, Taussig LM, and the Group Health Medical Associates. Breast feeding and lower respiratory tract illness in the first year of life. BMF 1989;299:946-9.

14 Sen GC, Ransohoff RM. Interferon-induced antiviral actions and their regulation. Adv Virus Res 1993;42:57-102.

15 Holt PG. A potential vaccine strategy for asthma and allied atopic diseases during early childhood. Lancet 1994;344: atopic dise 456 .

16 Martinez FD, Wright AL, Taussig LM, Holberg CJ, Halonen $M$, Morgan WJ. Asthma and wheezing in the first six years of life. N Engl $\mathcal{F}$ Med 1995;332:133-8.

17 Manetti R, Gerosa F, Giudizi MG, Biagiotti R, Parronchi $P$, Piccinni MP, et al. Interleukin 12 induces stable priming for interferon gamma (IFN-gamma) production during differentiation of human $\mathrm{T}$ helper $(\mathrm{Th}$ ) cells and transient IFN-gamma production in established Th2 cell clones. $\mathcal{F}$ Exp Med 1994;179:1273-83.

18 Leung R, Ho P. Asthma, allergy, and atopy in three southeast Asia populations. Thorax 1994;49:1205-10.

19 Flynn MDL. Respiratory symptoms of rural Fijian and Indian children in Fiji. Thorax 1994;49:1201-4.

20 von Mutius E, Martinez FD, Fritzsch C, Nicolai T, Roell $\mathrm{G}$, Thiemann HH. Prevalence of asthma and atopy in two areas of West and East Germany. Am $\mathcal{F}$ Respir Crit Care Med 1994;149:358-64.

21 Holt PG, Clough JB, Holt BJ, Baron-Hay MJ, Rose AH, Robinson BW, et al. Genetic 'risk' for atopy is associated with delayed postnatal maturation of T-cell competence. Clin Exp Allergy 1992;22:1093-9. 